\title{
Personalising Exercise and Nutrition Behaviours in Diabetes Lifestyle Prevention
}

\author{
Authors: \\ Ahmad Alkhatib \\ School of Health and Life Sciences, Teesside University, Middlesbrough, UK \\ Correspondence to drahmadalkhatib@gmail.com \\ Disclosure: \\ The author has declared no conflicts of interest. \\ Received: \\ 03.07.2019 \\ Accepted: \\ 14.11.2019 \\ Keywords: \\ Exercise, functional food, high intensity interval training (HIIT), high risk, lifestyle \\ prevention, omics, personalised medicine, sedentary, Type 2 diabetes mellitus \\ (T2DM), workplace. \\ Citation: \\ EMJ. 2020;5[1]:67-77.
}

\begin{abstract}
The alarming increase in global diabetes, especially Type 2 diabetes mellitus (T2DM), is affecting diverse populations and leading to consequent burdens of morbidities, mortalities, and healthcare costs. Physical activity and nutritional approaches form the cornerstones of lifestyle T2DM prevention. Advances in understanding an individual's behaviour and biological responses to different exercise conditions are concurrent with new personalised exercise and nutritional and behavioural tools effective for preventing T2DM and associated chronic diseases. Targeted exercise and nutrition interventions can be personalised across diverse population groups and different settings. Such approaches can benefit from evolving technologies embedding genomics, metabolomics, proteomics, and transcriptomics, together with behavioural reduction strategies such as addressing sedentary behaviour. This narrative review focusses on describing personalised lifestyle prevention approaches, which address different population needs and environmental settings. These methods can be better directed towards translating T2DM interventions and laboratory trials into sustainable, healthy behaviours, and help form personalised lifestyle T2DM prevention guidelines.
\end{abstract}

\section{INTRODUCTION}

The prevalence of Type 2 diabetes mellitus (T2DM) is rising globally, in some regions more than others, and overall diabetes rates are expected to reach one in 10 adults within the next decade.1,2 Societal and healthcare costs are some of the many burdens related to the increase in T2DM prevalence, which is also a risk factor of cardiovascular disease and premature mortality. ${ }^{2}$ Major T2DM risk factors include obesity, sedentary lifestyle, physical inactivity, poor nutrition, older age, and family history of diabetes. ${ }^{3}$

Lifestyle prevention is the major preventive measure of T2DM, as evidenced by major diabetes prevention studies across the globe. ${ }^{4-7}$ The risk reduction has been shown as an overall 58\% decrease in incidences of those with prediabetes and impaired glucose tolerance across different population groups from the Diabetes Prevention Program (DPP) and the Finnish Diabetes Prevention Study (DPS). ${ }^{4,5}$ It has also appeared lower (e.g., 28\% in the Di Qing study) and higher (e.g., $70 \%$ in a subcohort of the Finnish DPS). ${ }^{6-}$ 8 These lifestyle interventions have targeted high-risk individuals with various behavioural, multicomponent lifestyle prevention approaches 
(e.g., structured and unstructured exercise, nutrition, education, and counselling). For example, an average of 2.8 years follow up after implementation of a lifestyle modification programme, involving increased physical activity and weight loss, produced a 58\% reduction in the incidence of T2DM in those with prediabetes, compared to a 31\% reduction after taking metformin (an insulin-sensitising drug). ${ }^{5}$ Other dietary-only interventions such as the Mediterranean diet (MD) have retrospectively showed an association with reversing prediabetes into remission state after 5 years of adherence. ${ }^{9-11}$

Since the risks of diabetes and associated chronic diseases can be reversed by lifestyle interventions, it is important to personalise the intervention approaches that help form personalised behavioural guidelines instead of using a 'one size fits all' approach. Recent technological approaches (e.g., proteomics, metabolomics, genomics, and pharmacogenetics) have been publicised for personalising diabetes drug development.12,13 However, personalising complex lifestyle approaches in T2DM prevention, especially physical activity and nutrition behaviours, has received little attention. This narrative review translates key debates about lifestyle behaviours into specific T2DM recommendations and discusses how the most recent behavioural approaches, including physical activity and exercise intensity, sedentary lifestyle, and nutrition, can be individualised when targeted for T2DM prevention.

\section{PERSONALISED EFFECTIVENESS OF LIFESTYLE INTERVENTION (EXERCISE AND NUTRITION) AND THE PREVENTION PHASE}

Components of lifestyle include exercise, nutrition, and sleep, the first two of which have gained significant attention over the past three decades. Sleep research has also gathered recent research interest in T2DM prevention, ${ }^{14}$ though is beyond the scope of this review. Although selecting components for a lifestyle intervention varies across different T2DM programmes (single components such as structured or unstructured exercise, nutrition, unstructured or unsupervised education and counselling, or multicomponents), the timing of the intervention determines its component effectiveness. T2DM interventions can be classified into two timings or phases: a late phase (e.g., targeting T2DM risks such as prediabetes and obesity) or an early phase targeting the whole population (e.g., targeting all risk factors). Interventions with the early-phase interventions target all risk factors and engage multilevel stakeholders and policy makers (e.g., health, education, and sport authorities and nutrition providers)..$^{15}$ Late-phase interventions, which target sedentary, older, and postmenopausal individuals, and those with prediabetes with high cardiovascular disease (CVD) risk (elevated fasting blood glucose [FBG] and postprandial glucose [OGTT]), are likely to induce better effectiveness compared with those who are at reduced risk. Therefore, personalised preventive measures are most effective for those at high risk for T2DM in the late phase (Figure 1).

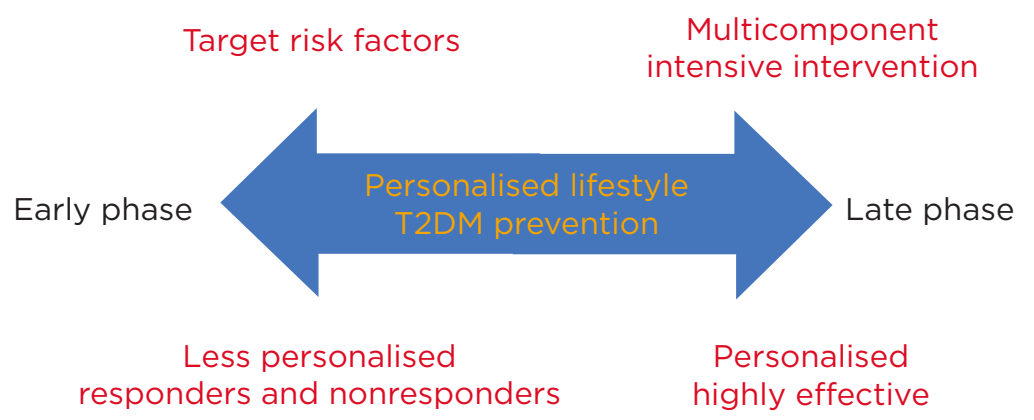

Figure 1: Schematic of personalised Type 2 diabetes mellitus prevention based on the intervention phase.

T2DM: Type 2 diabetes mellitus. 
However, it is important to consider that earlyphase targeting of T2DM risks can be irrespective of chronological age prior to developing T2DM, since T2DM is becoming increasingly prevalent among younger adults, teenagers, and even children. ${ }^{16}$

Evidence suggests that intraindividual variations in the response to a lifestyle prevention programme can vary by $>20 \%$. For example, variations in achieving physical activity T2DM prevention outcomes has been observed among a subset of older age groups with impaired glucose tolerance showing higher risk reduction (70\%), compared with the average response (58\%) following the same lifestyle prevention. ${ }^{4,8}$ This implies that achieving a better physical activity response is more easily achieved when personalised according to the higher risk groups in the late phase (e.g., older age groups with prediabetes).

On the other hand, effectiveness of recommended nutrient intake can also be influenced by the phase of the intervention, especially because nutrient deficiency is now a common symptom in individuals with obesity and diabetes. ${ }^{17,18}$ For those diagnosed with T2DM, preventing complications is an essential prevention approach which can be personalised based on their nutritional and lifestyle needs. Decreased levels of vitamins A, C, and E, which are associated with antioxidation, were observed in those with diabetes. This is possibly because of an increased need to control the excessive oxidative stress produced by abnormalities in glucose metabolism. ${ }^{17}$ The $\mathrm{B}$ group vitamins thiamine (B1), pyridoxine (B6), and biotin (B7) are decreased in T2DM individuals. ${ }^{18}$ Vitamin $\mathrm{D}$ and $\mathrm{K}$ modulatory effects on diabetes mechanisms have also been reported. ${ }^{17}$ For example, vitamin $D$ can improve insulin sensitivity and promote pancreatic $\beta$-cell survival by modulating the effects of cytokines and nuclear transcription factors such as NF-kB. ${ }^{17}$ However, such T2DM protective mechanisms are not necessarily achieved by vitamin D supplementation. Supplementation of vitamin D longitudinally (4,000 IU/day for 24 months in 2,423 adults with obesity and prediabetes) did not reduce T2DM incidence, despite increasing serum levels. ${ }^{19}$ Vitamin $C$ and Vitamin $\mathrm{E}$ supplementation have been shown to be effective in the short-term, ${ }^{20,21}$ while other micronutrients such as magnesium have also been suggested to enhance insulin sensitivity ${ }^{22,23}$ with promising effectiveness that is most likely dependent on the severity of the deficiency (Table 1). ${ }^{1719,21-25}$

Postulated antioxidation and anti-inflammatory effects of vitamins and minerals promote their benefits in the late-intervention phase for those with diagnosed T2DM with complications or those with multiple morbidities (Table 1).17,19,21-25 However, the evidence on the supplementation effectiveness of vitamins, minerals, and other antioxidants for preventing T2DM remains inconclusive, especially in the absence of welldesigned, longitudinal studies which combine supplementation with other functional diet and lifestyle approaches. Personalised T2DM prevention should consider the augmented effects of other lifestyle behaviours, especially physical activity strategies, ${ }^{3}$ to determine the effectiveness of nutrient supplementation.

\section{PERSONALISED COMPONENT CONTRIBUTION WITHIN LIFESTYLE TYPE 2 DIABETES MELLITUS INTERVENTIONS}

Current epidemiological evidence suggests that nutrition and physical activity guidelines are far from being upheld, with only $3 \%$ of Americans reported to have met T2DM risk-reduction guidelines. ${ }^{26}$ Meta-analyses have reported that similar barriers to implementing and scaling T2DM guidelines at real-world primary and secondary settings also exist in the UK. ${ }^{27}$ Implementing T2DM guidelines on an individual level is difficult, possibly attributable to multifaceted and confusing lifestyle recommendations, especially those related to physical activity and nutrition, together with a complex range of social, financial, behavioural, and organisational barriers. ${ }^{28}$ Furthermore, the relative contribution and effectiveness of each lifestyle component within an intervention (exercise behaviours, nutrition, and education) is also difficult to quantify. 
Table 1: Common micronutrient supplementation, postulated effects, and recommendations in Type 2 diabetes mellitus.

\begin{tabular}{|c|c|c|c|}
\hline Micronutrient & Metabolic function & $\begin{array}{l}\text { Supplementation } \\
\text { effectiveness }\end{array}$ & $\begin{array}{l}\text { Related recommendation } \\
\text { for T2DM prevention }\end{array}$ \\
\hline Vitamin B group & $\begin{array}{l}\text { Involved in the synthesis of } \\
\text { methionine, pyrimidine, and } \\
\text { purine bases. Its deficiency } \\
\text { due to DNA damage or } \\
\text { faulty repair is involved in } \\
\text { cancer, vascular diseases, } \\
\text { and some birth defects, } \\
\text { while a consequent } \\
\text { hyperhomocysteinemia is } \\
\text { also related to folic acid } \\
\text { deficiency. They are also a } \\
\text { risk factor for hypertension } \\
\text { and atherosclerosis. }{ }^{17}\end{array}$ & $\begin{array}{l}\text { Folic acid, pyridoxine, and } \\
\text { B12 or placebo produced } \\
\text { no difference in T2DM } \\
\text { incidence following } \\
\text { 7-year supplementation } \\
\text { in women with or without } \\
\text { cardiovascular disease risk } \\
\text { factors. }^{24}\end{array}$ & $\begin{array}{l}\text { Supplementation is not } \\
\text { necessary. Dietary intake } \\
\text { from dietary sources (e.g., } \\
\text { green leafy vegetables) is } \\
\text { recommended. }\end{array}$ \\
\hline Vitamin C & $\begin{array}{l}\text { Inversely correlated to } \\
\text { glycosylated haemoglobin } \\
\text { and fasting and } \\
\text { postprandial blood glucose } \\
\text { and oxidative stress. } .^{77} \text { Acts } \\
\text { as a potent antioxidant, } \\
\text { in collagen, neuropeptide, } \\
\text { and carnitine synthesis, } \\
\text { increasing iron absorption, } \\
\text { inhibiting histamine } \\
\text { release, and stimulating the } \\
\text { immune system. }{ }^{17,21}\end{array}$ & $\begin{array}{l}\text { Associated with } \\
\text { antioxidative enzymes in } \\
\text { T2DM patients. }{ }^{21} \text { 3-month } \\
\text { supplementation of } \\
\text { vitamins C and E decreased } \\
\text { hypertension and blood } \\
\text { glucose while increasing } \\
\text { superoxide dismutase and } \\
\text { glutathione levels. }{ }^{22}\end{array}$ & $\begin{array}{l}\text { Supplementation when } \\
\text { oxidative stress is high } \\
\text { is useful, and in the } \\
\text { short term in reducing } \\
\text { cardiovascular disease risk, } \\
\text { particularly hypertension in } \\
\text { individuals with T2DM. }\end{array}$ \\
\hline Vitamin D & $\begin{array}{l}\text { Can improve insulin } \\
\text { sensitivity and promote } \\
\text { pancreatic } \beta \text {-cell survival } \\
\text { by modulating the effects } \\
\text { of cytokines and nuclear } \\
\text { transcription factors such } \\
\text { as NF-kB. }{ }^{17}\end{array}$ & $\begin{array}{l}\text { A } 24-\text { month vitamin D } \\
\text { supplementation (a dose } \\
\text { of } 4,000 \text { IU/day) in } 2,423 \\
\text { adults with obesity and } \\
\text { prediabetes (criteria of: } \\
\text { HbA1c } 5.7-6.4 \% \text {; FPG } \\
100-125 \mathrm{mg} / \mathrm{dL} ; 2 \mathrm{~h}-\mathrm{OGTT} \\
140-199 \mathrm{mg} / \mathrm{dL} \text { ) did not } \\
\text { reduce T2DM incidence. }{ }^{19}\end{array}$ & $\begin{array}{l}\text { Supplementation may be } \\
\text { effective in those with prior } \\
\text { vitamin D deficiency. }\end{array}$ \\
\hline $\mathrm{Mg}^{2+}$ & $\begin{array}{l}\text { Regulates electrical activity } \\
\text { and insulin secretion } \\
\text { in pancreatic } \beta \text { cells. } \\
\text { Intracellular } \text { Mg }^{2+} \text { helps } \\
\text { the phosphorylation of } \\
\text { the insulin receptor and } \\
\text { other downstream signal } \\
\text { kinases of the target cells. } \\
\text { Low } \text { Mg }^{2+} \text { levels result in } \\
\text { defective tyrosine kinase } \\
\text { activity, postreceptor } \\
\text { impairment in insulin } \\
\text { action, and altered cellular } \\
\text { glucose transport and } \\
\text { utilisation, which promotes } \\
\text { peripheral insulin resistance } \\
\text { in T2DM. }{ }^{22}\end{array}$ & $\begin{array}{l}\text { Cross-sectional } \\
\text { associations showed } \mathrm{Mg}^{2+} \\
\text { levels correlated negatively } \\
\text { with fasting insulin levels, } \\
\text { and positively with the } \\
\text { lipid profile. There is a } 20 \% \\
\text { T2DM risk reduction for } \\
\text { each } 1 \mathrm{mg} / \mathrm{dL} \text { increase of } \\
\text { circulating } \mathrm{Mg}^{2+} \text { in those } \\
\text { with hypomagnesaemia } \\
<0.5 \text { mM (healthy } \\
\text { circulatory threshold is } 1 \\
\text { mM). }{ }^{24}\end{array}$ & $\begin{array}{l}\mathrm{Mg}^{2+} \text { supplementation } \\
\text { could ameliorate insulin } \\
\text { sensitivity, reducing } \\
\text { the risk of developing } \\
\text { T2DM in those with } \\
\text { hypomagnesaemia. }\end{array}$ \\
\hline Multivitamins and minerals & $\begin{array}{l}\text { Can enhance antioxidative } \\
\text { capacity in T2DM } \\
\text { patients. }{ }^{17,25}\end{array}$ & $\begin{array}{l}\text { Has been shown to reduce } \\
\text { the incidence of infections } \\
\text { in T2DM patients with } \\
\text { subclinical micronutrient } \\
\text { deficiency in older adults. }{ }^{23}\end{array}$ & $\begin{array}{l}\text { Supplementation may } \\
\text { be effective in advanced } \\
\text { states and in older T2DM } \\
\text { adults. }\end{array}$ \\
\hline
\end{tabular}


Meta-analysis of 23 lifestyle interventions that were beneficial in reducing T2DM risks (e.g., glycaemic control [FBG, 2-h OGTT, HbA1c], lipid profile [low-density lipoprotein, high-density lipoprotein, total cholesterol, triglycerides], blood pressure, and waist size) have poorly reported the relative contribution specific to either physical activity or dietary components. ${ }^{29}$ Understanding the contribution and effectiveness of exercise in T2DM risk-reduction interventions is essential for forming meaningful and scalable guidelines.

Individuals within the Finnish DPS who reported an increase in their exercise levels (moderate-tovigorous, low-to-moderate, or strenuous) were 63-65\% less likely to develop T2DM, which fell to $51 \%$ after adjustments for diet and body weight. ${ }^{8}$ This suggests a significant physical activity contribution and a dose-response relationship for T2DM prevention. Slentz et al. ${ }^{30}$ have applied the same model used within the first 6 months of the USA DPP to quantify the exercise components in 195 individuals with prediabetes. They assessed to what extent the amount of exercise is a contributor to improving glucose control outcomes of FBG, OGTT, and glucose area under the curve, and whether moderate or vigorous-intensity exercise is better for improving glucose homeostasis. They randomised sedentary older individuals with elevated FBG of 5.28-6.94 mmol/L, no CVD, and uncontrolled hypertension or diabetes into four groups during a 6-month intervention, based on the energy expended during physical activity interventions: 1) low levels of moderate intensity exercise (42 $\mathrm{kJ} / \mathrm{kg}$ of body weight/week [kkw]) equivalent to walking exercise (approximately $16.0 \mathrm{~km} /$ week at $50 \%$ of their $\mathrm{O}_{2}$ uptake $\left[\mathrm{V}_{2}\right]_{\text {peak }}$ ); 2) high levels of moderate intensity exercise (67 kkw) equivalent to walking exercise (approximately $22.3 \mathrm{~km} /$ week at $50 \% \mathrm{VO}_{2 \text { peak }}$ ); 3) high levels of vigorous intensity exercise (67 kkw) equivalent to Group 2 (approximately $22.3 \mathrm{~km} /$ week at $75 \% \mathrm{~V}_{2 \text { eak }}$ ); and 4) moderate intensity exercise (42 kkw) equivalent to Group 1 walking exercise (approximately $16.0 \mathrm{~km}$ at $50 \% \dot{\mathrm{V}}_{2 \text { peak }}$ ) combined with diet and weight loss (7\%) to mimic the first 6 months of the DPP. Results showed significantly better glycaemic control improvement (OGTT and glucose area under the curve) in the two groups who followed moderate exercise (effect size: 0.60 and 0.73 ) than the vigorous exercise group (effect size: 0.21), and that the combined approach (Group 4) further induced a decrease in FBG (effect size: 0.71 versus approximately 0.17 in the remaining groups). The results suggested that moderate-intensity exercise in the form of 'easy to follow walking' was more effective than the same amount of vigorous-intensity exercise for T2DM glycaemic outcomes.

\section{ISSUES WITH EXERCISE INTENSITY FOR PERSONALISED TYPE 2 DIABETES MELLITUS PREVENTION}

Levels of physical activity are known to be associated with reduced metabolic and cardiovascular risks including T2DM and reduced all-cause mortality in a dose-response relationship. ${ }^{31}$ Exercise prescriptions for T2DM have often involved significantly different volumes and durations of exercise types: low intensity exercise (e.g., spending less time sitting), moderate-to-vigorous intensity exercise (150-300 $\mathrm{min} /$ week), heavy or vigorous intensity exercise (75 min/week), or severe intensity exercise (20 min/week), combined with strength training exercises (2/week). ${ }^{2,32}$ This places a significant burden and confusion to those at risk or with T2DM to meet almost $300 \mathrm{~min} /$ week of exercise, especially considering the recent contradictory recommendation of performing shorter bouts of high intensity exercise. ${ }^{2,33}$

The recently proposed high intensity interval exercise training (HIIT) was based on promoting time efficiency because this method can take less time to achieve comparable outcomes than lower intensity exercise. ${ }^{34,35}$ For example, six HIIT sessions (10 $\times 60$ sec cycling bouts eliciting $90 \%$ maximal heart rate, interspersed with $60 \mathrm{sec}$ rest) have been attributed to modulate postprandial and 24-hour glucose control, and muscle biopsy mitochondrial capacity biomarkers. ${ }^{35}$ The Homeostatic Model of Insulin Resistance (HOMA-IR) and OGTT response were also changed following a single training session at this intensity in selected T2DM patients. ${ }^{36}$ However, the short-term nature of the studies (only 2 weeks intervention, early T2DM diagnosis, strict laboratory supervision, lack of long-term adherence), makes it difficult to translate their recommendation into real-life settings for T2DM prevention. Other high-risk 
groups such as overweight women, who followed a HIIT programme over 12 weeks, showed no improvement in insulin sensitivity despite reduced total and abdominal body fat percentage. ${ }^{37}$ Furthermore, simply changing the time of day that the exercise is performed at could negate HIIT effectiveness in T2DM patients, and it has been shown that an afternoon HIIT is superior to a morning HIIT in enhancing T2DM outcomes. ${ }^{38}$ Concerns have also been raised about HIIT safety and feasibility as a public health strategy. ${ }^{39} \mathrm{~A}$ recent meta-analysis involving 411 heart failure patients concluded that HIIT is not superior to other types of lower intensity exercise when isocaloric exercise protocols were compared. 40 Furthermore, T2DM risk reduction among 48,000 individuals who engaged in either vigorous running exercise or walking behaviours was almost the same (12.1\% versus $12.3 \%$ for running versus walking, respectively). ${ }^{41}$

Promoting HIIT had originally been associated with athletic performance for different endurance sports. ${ }^{42}$ As such, HIIT was defined as repeated short-to-moderate duration exercise sessions lasting $10 \mathrm{sec}$ to $5 \mathrm{~min}$ at a range of high intensities, provided they are higher than anaerobic threshold (based on lactate or ventilatory threshold). Such sessions were separated by either brief periods of low-intensity work or inactivity that allow a partial, but often not a full, recovery. ${ }^{43}$ There was an intensity range flexibility in the original definition, which was based on stressing the physiological systems that are used during a specific endurance-type exercise to a higher level than that usually required during the activity. ${ }^{42}$ Since HIIT is an acknowledged heavy exercise intensity physiological domain which determines a plethora of cardiovascular, respiratory, and metabolic responses, its training effectiveness can be attributed to a dose-response relationship. Exercise intensity domains, including those of HIIT and associated physiological responses (e.g., blood lactate concentration, oxygen uptake, and respiratory quotient), have been well known since the turn of the $20^{\text {th }}$ century. ${ }^{44}$

Undoubtedly, a higher dose of intensity exercise, such as those within HIIT heavy-domain or strength type exercises, induce an elevated physiological response compared to lowerintensity exercise. This has been demonstrated in medium-term training effects reported on selected proteomics and transcriptomics protein translational machinery following either HIIT or strength training, compared with lower-intensity, moderate exercise in younger and older adults. ${ }^{45}$ However, the effectiveness of each type (HIIT versus strength) varied significantly amongst the group, with older adults benefiting more from strength training given the age-related muscle atrophy risks. ${ }^{45}$ Whether, and how, effects of HIIT can be found longitudinally in those with prediabetes or T2DM is as yet unknown. Interventions in real-life settings where long-term adherence, self-referral, injury, and risk reduction matter, reported higher injury prevalence (resulting in lower adherence rate) in sedentary individuals with T2DM who trained using HIIT compared to that of moderate-intensity exercise. ${ }^{46}$ Long-term effectiveness of using heavy types of exercise training with a specific definition is needed to determine whether HIIT can be implemented at an individual level. Perhaps under continual specialist supervision, HIIT-type interventions in combination with appropriate behavioural lifestyle support can be effective in high-risk individuals. However, population scalability for T2DM prevention favours lower intensity types of physical activity. ${ }^{47}$

\section{COMBINING PERSONALISED BEHAVIOURAL NUTRITION, EDUCATION, AND PHYSICAL ACTIVITY APPROACHES}

The suggestion is that an easier to follow intervention design may be better for individuals' adherence and primary T2DM outcomes than complex interventions, especially if a simplified approach is personalised by using or developing technology-based tools for both diet and exercise. For example, recently reported physical activity accelerometer-based interventions have been shown to increase physical activity levels, concurrent with improved diabetes and CVD outcomes in sedentary T2DM patients in the ADDITION-Plus study after a 4-year follow up. $^{48}$ T2DM prevention counselling, behavioural or individualised toolboxes of adherence strategies', materials to address ethnic diversity, training, feedback, and clinical support have been discussed in details elsewhere as part of large T2DM prevention programmes. ${ }^{4,5}$ For example, 
improvement in T2DM outcomes and related quality of life have been reported in people with T2DM attending a behavioural programme (DESMOND), ${ }^{49}$ whilst other types of diabetes have also benefitted from similar diet and physical activity counselling programmes including Type 1 diabetes mellitus (DAFNE) and gestational diabetes. ${ }^{50}$ Determining the relative contribution and effectiveness of counselling and behavioural tools within a multi-component T2DM requires further research.

Nutritional education and dietary counselling are essential within primary, secondary, and tertiary T2DM clinical care settings, and are used in screening and evaluating the dietary behaviour of people with diabetes. It helps individuals to understand food and beverage consumption behaviours, and develop skills needed to better manage their diabetes and prevent the development of related comorbidities. ${ }^{51}$ Although nutritional education is a personalised method for preventing T2DM, individual counselling is laborious and cost-intensive; however, the use of technology such as mobile phone apps could be an excellent adjuvant method in personalising T2DM lifestyle prevention. Recent systematic reviews and meta-analyses have concluded that diabetes management mobile phone apps can be effective in improving selfefficacy, disease knowledge, physician-patient communication, and reducing diabetes incidence through delivering information, education, selfmanagement, therapeutic advice, and drug guidance. ${ }^{52,53}$ However, despite the availability of $>120$ downloadable apps for personal devices, only a few (approximately 11) appear to provide specific feedback for nutrition and exercise behaviours related specifically to T2DM or prediabetes. Additionally, these are limited to measuring HbA1c as a primary T2DM outcome while secondary outcomes are only addressed through a focus on persuasive weight management and behavioural lifestyle changes, which may explain their benefits. ${ }^{52}$

Overall, whether facilitated face-to-face or through a phone app, dietary counselling still heavily relies on teaching caloric and carbohydrate counting (e.g., identifying sources of carbohydrate in reported foods, portion estimates using measuring cups and smart food scales based on food composition tables, mobile apps, and websites).51,54 Nonetheless, technologies provide great promise in providing personalised behavioural approaches to prevent T2DM.

In the context of forming personalised lifestyle recommendations, it is important to note that caloric restriction for weight loss may not be an effective T2DM prevention strategy. Improvements in T2DM or associated cardiovascular outcomes were not often matched by weight loss, especially when caloric restriction was used. For example, the MD, which is associated with reduced T2DM, CVD, and mortality risk, is not a caloric restrictive diet. ${ }^{10,11}$ Interventions with a MD that reduced other cardiometabolic risks in high-risk individuals have also reported no change in body weight. ${ }^{55,56}$ Large T2DM longitudinal, multicomponent interventions that used components of caloric restriction for weight loss have reported minimal changes (e.g., $2 \mathrm{~kg}$ ), ${ }^{30}$ or no body weight change. ${ }^{48}$ Results from a large caloric restriction-induced weight-loss intensive intervention (combined with physical activity and dietary counselling) in sedentary T2DM individuals demonstrated an improved $\mathrm{HbA1c}$ but no reduction in cardiovascular mortality, which suggests that intensive weight loss may not be a sufficient outcome for cardiovascular events in those with T2DM. ${ }^{57}$ Therefore, T2DM dietary recommendations should distinguish between qualitative versus quantitative composition of diet (e.g., a healthy nutritional plan versus plain caloric restriction). On the other hand, in terms of exercise recommendations that sustain behavioural change, the evidence from comparing large-scale interventions in individuals with prediabetes or diagnosed T2DM suggests that long-term adherence can be achieved by simple lifestyle modifications when they are targeted towards specific T2DM outcomes (Table 2). . $^{30,48,57}$

Recently, there has been growing evidence on the association between sedentary behaviour and several chronic diseases, including diabetes..$^{58}$ Therefore, it is important to understand the specific determinants of sedentary-related risks and their association with diabetes incidence and factors across different populations and environmental settings in order to devise effective targeted and personalised intervention strategies. Sedentary behaviour (e.g., 1 hour of watching TV) is associated with increased T2DM risk and allcause mortality, independent of physical activity levels. ${ }^{59-61}$ 
Table 2: Recommendations for physical activity and exercise for those with Type 2 diabetes mellitus based on longitudinal interventions.

\begin{tabular}{|c|c|c|c|}
\hline $\begin{array}{l}\text { Lifestyle T2DM } \\
\text { interventions }\end{array}$ & Intervention method & $\begin{array}{l}\text { T2DM intervention } \\
\text { outcomes }\end{array}$ & T2DM recommendation \\
\hline $\begin{array}{l}\text { Randomised intervention } \\
\text { trial with } 195 \text { individuals } \\
\text { with prediabetes (Slentz et } \\
\text { al., } 30 \text { 2016). }\end{array}$ & $\begin{array}{l}\text { T2DM outcomes (FBG, } \\
\text { OGTT) in four groups: } \\
\text { 1) Mod-LV ( } 42 \mathrm{kkw} \text {, } \\
\text { approximately } 16 \mathrm{~km} / \text { week } \\
\text { at } 50 \% \dot{\mathrm{VO}}_{2 \text { peak }} \text { ). } \\
\text { 2) Mod-HV ( } 67 \mathrm{kkw} \text {, } \\
\text { approximately } 22 \mathrm{~km} / \text { week } \\
\text { at } 50 \% \dot{\mathrm{VO}}_{2 \text { peak }} \text { ). } \\
\text { 3) Vig-HV ( } 67 \mathrm{kkw} \text { at } 75 \% \\
\dot{\mathrm{VO}}{ }_{2 \text { peak }} \text { ). } \\
\text { 4) Diet/weight loss and LV } \\
\text { (42 kkw at } 50 \% \dot{\mathrm{VO}}_{2 \text { peak }} \text { ). }\end{array}$ & $\begin{array}{l}\text { Diet and exercise induced } \\
\text { better FBG. } \\
\text { Only moderate exercise } \\
\text { enhanced OGTT. } \\
\text { Moderate exercise was } \\
\text { more effective than the } \\
\text { same volume of vigorous } \\
\text { exercise, with an } 82 \% \\
\text { adherence rate. }\end{array}$ & $\begin{array}{l}\text { Moderate exercise (e.g., } \\
\text { simple intervention of } \\
\text { walking with counselling) } \\
\text { is as effective for primary } \\
\text { T2DM outcomes as } \\
\text { vigorous exercise with } \\
\text { intensive treatment rate, } \\
\text { with better adherence } \\
\text { rates. }\end{array}$ \\
\hline $\begin{array}{l}\text { Prospective } 328 \text { T2DM } \\
\text { cohort ADDITTION-Plus } \\
\text { followed for } 4 \text { years (Lamb } \\
\text { et al., }{ }^{48} \text { 2016). }\end{array}$ & $\begin{array}{l}\text { HR-based accelerometer- } \\
\text { measured PAEE to reduce } \\
\text { WC, BP, and CVD risk } \\
\text { associated with sedentary } \\
\text { lifestyle and low PA. }\end{array}$ & $\begin{array}{l}\text { PA accelerometer } \\
\text { intervention increased } \\
\text { PAEE and CRF and } \\
\text { reduced sedentary related } \\
\text { CVD risks in T2DM patients. }\end{array}$ & $\begin{array}{l}\text { Simply increasing PA } \\
\text { by accelerometery } \\
\text { interventions can be } \\
\text { effective in reducing CVD } \\
\text { risk in individuals with } \\
\text { T2DM. }\end{array}$ \\
\hline $\begin{array}{l}\text { Intensive intervention to } \\
\text { prevent CVD mortality. } \\
\text { Look AHEAD cohort with } \\
5,145 \text { overweight T2DM } \\
\text { patients (Wing et al.,57 } \\
\text { 2013). }\end{array}$ & $\begin{array}{l}1 \text { year (within } 5 \text { years) with } \\
15 \text { years follow-up. } \\
\text { Intensive calorie restriction } \\
\text { weight loss and increased } \\
\text { PA versus counselling. } \\
\text { CVD-mortality (MI/stroke, } \\
\text { angina). }\end{array}$ & $\begin{array}{l}\text { Weight loss ( } 8.6 \text { versus } \\
0.7 \% \text { at Year } 1 ; 6.0 \% \text { versus } \\
3.5 \% \text { at Year } 5 \text { ) initially } \\
\text { improved CRF and HbA1c. } \\
\text { It did not reduce CVD- } \\
\text { mortality ( } 403 \text { versus } 418 \text { ). }\end{array}$ & $\begin{array}{l}\text { Specify the targeted } \\
\text { T2DM outcomes. Intensive } \\
\text { intervention that is good } \\
\text { for reducing T2DM risks } \\
\text { may not be good for CVD } \\
\text { mortality. Weight-loss } \\
\text { caloric restriction may } \\
\text { not be a sufficient T2DM } \\
\text { prevention strategy. }\end{array}$ \\
\hline
\end{tabular}

BP: blood pressure; CRF: cardiovascular fitness; CVD: cardiovascular disease; FBG: fasting blood glucose; HbA1c: haemoglobin A1c test; HR: heart rate; kkw: kJ per kg of body weight per week; MI: myocardial infarction; ModHV: moderate high-volume physical activity; Mod-LV: moderate low-volume physical activity; OGTT: oral glucose tolerance test; PA: physical activity; PAEE: physical activity energy expenditure; T2DM: Type 2 diabetes mellitus; Vig$\mathrm{HV}$ : vigorous high-volume physical activity; $\dot{\mathrm{V}}_{2 \text { peak }}$ : peak oxygen uptake; WC: waste circumference.

Interestingly, this risk can be in both leisurebased and workplace-based sedentariness. ${ }^{62}$ Therefore, individually targeted workplacespecific interventions to reduce sedentary-related T2DM risks can be effective. For example, it has been shown that a 10-week exercise intervention in 54 sedentary university employees (aged 45-55 years old) enhanced cardiorespiratory outcomes (e.g., ventilatory threshold, cardiorespiratory capacity) irrespective of their job role, but not sex, for which women responded better across administrative and academic job roles. ${ }^{56,63}$
Intervention in this high-risk group was based on increasing physical activity levels during working hours (e.g., lunch time) to a tolerable level, such as using individual's perceived effort of exertion and using a self-selected intensity lasting $<1$ hour and falling within an effective training range (individualised ventilatory threshold), which was long enough to induce significant riskreduction and CVD benefits. However, younger sedentary university workplace groups such as university students can tolerate and adhere to a more vigorous physical activity intensity. 
A 10-week intervention involving 158 students relied on a variety of sports games to reduce cardiovascular risk factors such as blood pressure and cardiorespiratory capacity, as well as weight and fat-loss outcomes. ${ }^{64}$ Other high-risk groups included postmenopausal women with T2DM, in which exercise training induced a significant vascular endothelial function improvement when exercise was combined with a nutritional approach based on the MD.56 Therefore, sedentary-associated risks, which are carefully evaluated across different populations and settings, can be directly reduced using an individualised approach targeted at specific sedentary related risks.

Individuals with T2DM or its complications showed higher sedentary behaviour levels than their nondiabetic counterparts. ${ }^{65}$ A doseresponse relationship has been reported between the volume of uninterrupted sitting time and poor metabolic health. ${ }^{66}$ Poor glycaemic control (reduced insulin sensitivity, FBG, and OGTT) has been associated with sitting times and patterns in individuals with T2DM. ${ }^{67}$ Recent personalised assessments of sedentary behaviour using accelerometers have also shown a prevalence of concurrent sedentariness (sitting $>9$ hours/day) and insufficient physical activity ( $<30 \mathrm{~min} /$ day of moderate activity) in those with T2DM and obesity, ${ }^{68}$ and amongst women at high risk of gestational diabetes. ${ }^{69}$

Similar sedentary associations with poor glycaemic control and reduced insulin sensitivity were observed in a 1-year study following and tracking physical activity levels using concurrent wrist-worn accelerometery and continuous glucose monitoring sensors in those with T2DM. ${ }^{70}$ Such objective assessment tools help to provide an individualised intervention for sedentary individuals with T2DM. Sedentary behaviourrelated diabetes risks should be targeted with personalised interventions based on their specific lifestyle determinants and associations (e.g., sex, age, occupation, workplace, and environmental risk factors). ${ }^{68-71}$

\section{CONCLUSIONS}

Preventing T2DM relies primarily on changing lifestyle behavioural components, especially physical activity and nutrition. A personalised behavioural approach can support both earlyand late-phase interventions, targeted physical activity, and nutritional guidelines for specific high-risk populations for different settings and risk factors. Quantifying the exercise components within large-scale interventions can inform how much intensity, volume, and mode is required to maximise T2DM risk reduction benefits. The recent high intensity exercise recommendations for T2DM require more personalisation, especially given the concerns about their scalability and longterm adherence. Mobile technology advances offer objective assessment, intervention exercise, nutrition, and counselling tools which can target high-risk individuals, especially when integrated with other direct medical approaches and targeted at different settings such as workplaces. Personalising lifestyle behaviours offers a holistic understanding which could enhance T2DM prevention guidelines.

\section{References}

1. International Diabetes Federation (IDF). IDF Diabetes Atlas Seventh Edition. 2015. Available at: https:// www.idf.org/e-library/epidemiologyresearch/diabetes-atlas/13-diabetesatlas-seventh-edition.html. Last accessed: 01 April 2019

2. World Health Organization (WHO). Global report on diabetes. 2016. Available at: http://www.who.int/ diabetes/global-report/en/. Last accessed: 01 April 2019

3. Alkhatib A, Tuomilehto J. "Lifestyle Diabetes Prevention," Huhtaniemi I, Martini L (eds.), Encyclopaedia of Endocrine Diseases (2018) 2nd edition, Amsterdam: Elsevier, pp.14859.

4. Tuomilehto $\mathrm{J}$ et al. Prevention of Type 2 diabetes mellitus by changes in lifestyle among subjects with impaired glucose tolerance. N Engl J Med. 2001;344(18):1343-50.

5. Knowler WC et al. Diabetes Prevention Program Research Group. Reduction in the incidence of Type 2 diabetes with lifestyle intervention or metformin. N Engl J Med. 2002;346(6):393-403

6. Ramachandran A et al. Indian
Diabetes Prevention Programme (IDPP). The Indian Diabetes Prevention Programme shows that lifestyle modification and metformin prevent Type 2 diabetes in Asian Indian subjects with impaired glucose tolerance (IDPP-1). Diabetologia. 2006;49(2):289-97.

7. Pan XR et al. Effects of diet and exercise in preventing NIDDM in people with impaired glucose tolerance: the Da Qing IGT and diabetes study. Diabetes Care. 1997;20:537-44.

8. Laaksonen et al. Finnish Diabetes 
Prevention Study. Physical activity in the prevention of Type 2 diabetes: the Finnish Diabetes Prevention Study. Diabetes. 2005;54(1):158-65.

9. Esposito $\mathrm{K}$ et al. The effects of a Mediterranean diet on the need for diabetes drugs and remission of newly diagnosed Type 2 diabetes: follow-up of a randomized trial. Diabetes Care. 2014;37(7):1824-30.

10. Estruch R et al. Primary prevention of cardiovascular disease with a Mediterranean diet. N Engl J Med. 2013;368:1279-90.

11. Salas-Salvadó $\mathrm{J}$ et al. Prevention of diabetes with Mediterranean diets: a subgroup analysis of a randomized trial. Ann Intern Med. 2014;160(1):1-10.

12. Malandrino N, Smith RJ. Personalized medicine in diabetes. Clin Chem. 2011;57(2):231-40.

13. Klonoff DC. Personalized medicine for diabetes. J Diabetes Sci Technol. 2008;2(3):335-41.

14. Zimmet P et al. The Circadian Syndrome: is the metabolic syndrome and much more! J Intern Med. 2019;286(2):181-91.

15. Tuomilehto J, Schwarz PE. Preventing diabetes: early versus late preventive interventions. Diabetes Care. 2016;39(Suppl 2):S115-20

16. Weigensberg MJ, Goran MI. Type 2 diabetes in children and adolescents. Lancet. 2009;373(9677):1743-4.

17. Valdés-Ramos $R$ et al. Vitamins and Type 2 diabetes mellitus. Endocr Metab Immune Disord Drug Targets. 2015;15(1):54-63

18. Astrup A, Bügel S. Overfed but undernourished: recognizing nutritional inadequacies/deficiencies in patients with overweight or obesity. Int J Obes (Lond) 2019;43(2):219-32.

19. Pittas AG et al. Vitamin D supplementation and prevention of Type 2 diabetes. $N$ Engl J Med. 2019;381(6):520-30

20. Rafighi $Z$ et al. Association of dietary vitamin $\mathrm{C}$ and $\mathrm{e}$ intake and antioxidant enzymes in Type 2 diabetes mellitus patients. Glob J Health Sci. 2013;5(3):183-7.

21. Mazloom et al. Effect of vitamin C supplementation on postprandial oxidative stress and lipid profile in Type 2 diabetic patients. Pak J Biol Sci. 2011;14(19):900-4

22. Kostov K. Effects of magnesium deficiency on mechanisms of insulin resistance in Type 2 diabetes: focusing on the processes of insulin secretion and signaling. Int J Mol Sci. 2019;20(6).pii:E1351.

23. Spiga $\mathrm{R}$ et al. Are circulating $\mathrm{Mg} 2+$ levels associated with glucose tolerance profiles and incident Type 2 diabetes? Nutrients. 2019;11(10). pii:E2460.
24. Song $Y$ et al. Effect of homocysteinelowering treatment with folic Acid and $B$ vitamins on risk of Type 2 diabetes in women: a randomized, controlled trial. Diabetes. 2009;58(8):1921-8.

25. Song $Y$ et al. Multivitamins, individual vitamin and mineral supplements, and risk of diabetes among older U.S adults. Diabetes Care. 2011;34(1):10814.

26. Siegel KR et al. Prevalence of major behavioral risk factors for Type 2 diabetes. Diabetes Care. 2018;41(5):1032-9.

27. Public Health England (PHE). A systematic review and meta-analysis assessing the effectiveness of pragmatic lifestyle interventions for the prevention of Type 2 diabetes mellitus in routine practice. 2015. Available at: https://assets.publishing service.gov.uk/government/uploads/ system/uploads/attachment data/ file/733053/PHE_Evidence_ Review_of_diabetes_prevention_ programmes- FINAL.pdf. Last accessed: 01 June 2019

28. Midha I. Discerning diabetes selfmanagement for optimal care. BOAJ Diabetes. 2017;3(1):1-5.

29. Dunkley AJ et al. Diabetes prevention in the real world: effectiveness of pragmatic lifestyle interventions for the prevention of Type 2 diabetes and of the impact of adherence to guideline recommendations: a systematic review and meta-analysis. Diabetes Care. 2014:37(4):922-33.

30. Slentz CA et al. Effects of exercise training alone vs a combined exercise and nutritional lifestyle intervention on glucose homeostasis in prediabetic individuals: a randomised controlled trial. Diabetologia. 2016;59(10):2088-98.

31. Myers $\mathrm{J}$ et al. Exercise capacity and mortality among men referred for exercise testing. $\mathrm{N}$ Engl J Med. 2002;346(11):793-801.

32. Colberg SR et al. Physical activity/ exercise and diabetes: a position statement of the American Diabetes Association. Diabetes Care. 2016;39(11):2065-79

33. Diabetes UK. High intensity interval training (HIIT). Available at: https:// www.diabetes.co.uk/high-intensityinterval-training.html. Last accessed: 10 April 2019

34. Gibala MJ, McGee SL. Metabolic adaptations to short-term highintensity interval training: a little pain for a lot of gain? Exerc Sport Sci Rev. 2008:36(2):58-63.

35. Little JP et al. Low-volume highintensity interval training reduces hyperglycemia and increases muscle mitochondrial capacity in patients with Type 2 diabetes. J Appl Physiol (1985). 2011:111(6):1554-60.

36. Shaban $\mathrm{N}$ et al. The effects of a 2 week modified high intensity interval training program on the homeostatic model of insulin resistance (HOMAIR) in adults with Type 2 diabetes. J Sports Med Phys Fitness. 2014;54:203-9.

37. Gillen JB et al. Interval training in the fed or fasted state improves body composition and muscle oxidative capacity in overweight women. Obesity. 2013;21:2249-55.

38. Savikj $M$ et al. Afternoon exercise is more efficacious than morning exercise at improving blood glucose levels in individuals with Type 2 diabetes: a randomised crossover trial. Diabetologia. 2019;62(2):233-7.

39. Biddle SJ, Batterham AM. Highintensity interval exercise training for public health: a big HIT or shall we HIT it on the head? Int J Behav Nutr Phys Act. 2015;12:95.

40. Gomes Neto $M$ et al. High intensity interval training versus moderate intensity continuous training on exercise capacity and quality of life in patients with heart failure with reduced ejection fraction: a systematic review and meta-analysis. Int J Cardiol. 2018;261:134-41.

41. Williams PT, Thompson PD. Walking versus running for hypertension, cholesterol, and diabetes mellitus risk reduction. Arterioscler Thromb Vasc Biol. 2013;33(5):1085-91.

42. Laursen $P B$, Jenkins DG. The scientific basis for high-intensity interval training: optimising training programmes and maximising performance in highly trained endurance athletes. Sports Med. 2002:32(1):53-73.

43. Sardinha LB et al. Sedentary patterns, physical activity, and cardiorespiratory fitness in association to glycemic contro in Type 2 diabetes patients. Front Physiol. 2017;8:262.

44. Hill AV et al. Muscular exercise, lactic acid and the supply and utilisation of oxygen. Parts VII-VIII. Proc R Soc Lond B Biol Sci.1924;97:155-76.

45. Robinson MM et al. Enhanced protein translation underlies improved metabolic and physical adaptations to different exercise training modes in young and old humans. Cell Metab. 2017;25(3):581-92.

46. Lunt $\mathrm{H}$ et al. High intensity interva training in a real world setting: a randomized controlled feasibility study in overweight inactive adults, measuring change in maximal oxygen uptake. PLoS One. 2014;9(1):e83256.

47. Aziz Z et al. A systematic review of real-world diabetes prevention programs: learnings from the last 15 years. Implement Sci. 2015;10:172.

48. Lamb MJE et al, ADDITION-Plus study team. Prospective associations between sedentary time, physical activity, fitness and cardiometabolic 
risk factors in people with Type 2 diabetes. Diabetologia. 2016;59(1):11020.

49. Davies MJ et al. Effectiveness of the diabetes education and self management for ongoing and newly diagnosed (DESMOND) programme for people with newly diagnosed Type 2 diabetes: cluster randomised controlled trial. BMJ. 2008;336(7642):491-5.

50. Hopkins D et al. Improved biomedical and psychological outcomes 1 year after structured education in flexible insulin therapy for people with Type 1 diabetes: the U.K. DAFNE experience. Diabetes Care. 2012;35(8):1638-42.

51. Warshaw S, Kulkarni K. Complete Guide to Carb Counting (2004). Arlington: American Diabetes Association, pp.1-245.

52. Hou $\mathrm{C}$ et al. Do mobile phone applications improve glycemic control ( $\mathrm{HbA1C})$ in the self-management of diabetes? A systematic review, meta-analysis, and GRADE of 14 Randomized Trials. Diabetes Care. 2016;39(11):2089-95.

53. Chavez S et al. Mobile apps for the management of diabetes. Diabetes Care. 2017;40(10):e145-6.

54. Alkhatib A et al. Functional foods and lifestyle approaches for diabetes prevention and management. Nutrients. 2017;9(12)pii:E1310

55. Alkhatib A. High prevalence of sedentary risk factors amongst university employees and potential health benefits of campus workplace exercise intervention. Work. 2015;52(3):589-95.
56. Alkhatib A, Klonizakis M. Effects of exercise training and Mediterranean diet on reducing post-menopausal vascular risk. Clinic Hemorheol Microcirc. 2014;57:33-47.

57. Wing RR et al. Look AHEAD Research Group. Cardiovascular effects of intensive lifestyle intervention in Type 2 diabetes. N Engl J Med. 2013;369(2):145-54

58. Alkhatib A. Sedentary Lifestyle, Predictive Factors, Health Risks and Physiological Implications (2016), New York: Nova Science Publishers, pp.1-163.

59. Veerman JL et al. Television viewing time and reduced life expectancy: a life table analysis. Br J Sports Med. 2012;46(13):927-30

60. Grøntved A, Hu FB. Television viewing and risk of Type 2 diabetes, cardiovascular disease, and all-cause mortality: a meta-analysis. JAMA. 2011;305(23):2448-55.

61. Biswas A et al. Sedentary time and its association with risk for disease incidence, mortality, and hospitalization in adults: a systematic review and meta-analysis. Ann Int Med. 2015;162:123-32.

62. Turi BC et al. TV viewing time is associated with increased all-cause mortality in Brazilian adults independent of physical activity. Scand J Med Sci Sports. 2018;28(2):596-603.

63. Alkhatib A. Sedentary risk factors across genders and job roles within a university campus workplace: preliminary study. J Occup Health. 2013; 55(3):218-24.
64. Kneffel Z et al. Cardiovascular risk factors and their responses to a 10 weeks training program in young Qatari adults. Obes Res Open J. 2015;2(2):57-63.

65. Liese AD et al. Physical activity, sedentary behaviors, physical fitness, and their relation to health outcomes in youth with Type 1 and Type 2 diabetes: a review of the epidemiologic literature. J Sport Health Sci. 2013;2(1):21-38.

66. Owen $\mathrm{N}$ et al. Too much sitting: the population-health science of sedentary behavior. Exerc Sport Sci Rev. 2010;38(3):105-13.

67. Sardinha LB et al. Sedentary patterns, physical activity, and cardiorespiratory fitness in association to glycemic control in Type 2 diabetes patients. Front Physiol. 2017;8:262.

68. Mathe $\mathrm{N}$ et al. Correlates of accelerometer-assessed physical activity and sedentary time among adults with Type 2 diabetes. Can J Public Health. 2017;108(4):e355-61

69. Fazzi C et al. Sedentary behaviours during pregnancy: a systematic review. Int J Behav Nutr Phys Act. 2017;14(1):32

70. Fritschi $\mathrm{C}$ et al. Association between daily time spent in sedentary behavior and duration of hyperglycemia in Type 2 diabetes. Biol Res Nurs. 2016;18(2):160-6.

71. Lim MS et al. Leisure sedentary time is differentially associated with hypertension, diabetes mellitus, and hyperlipidemia depending on occupation. BMC Public Health. 2017;17(1):278. 